\title{
THE USE OF DUNITE MINI-LUMPS IN THE SINTERING PROCESS*
}

\author{
Enrique Francisco Somolinos Garcia-Morales ${ }^{1}$ \\ Javier Martinez Rubio 2
}

\begin{abstract}
In this paper we will discuss the benefits of a very innovative way of introducing $\mathrm{MgO}$ in the blast furnace operation through the sinter, using mini lumps of dunite. By changing the traditional way of using an MgO bearing material in fines form (particle smaller than $5 \mathrm{~mm}$ ), most of the $\mathrm{MgO}$ inserted material behaves as inert during the sintering process, with the effect of having the following parameters (among others) improved: productivity at the sintering bed, permeability inside the blast furnace, energy consumption, stability of the operation.
\end{abstract}

Keywords: Sinter; Dunite; Mini-Lump; MgO; Innovation.

$1 \quad$ Mining Engineer, Energy, Commercial Director, Oviedo, Asturias, Spain.

2 Mining Engineer, Managing Director, Oviedo, Asturias, Spain.

* Technical contribution to the $44^{\text {th }}$ Ironmaking and Raw Materials Seminar, $15^{\text {rd }}$ Brazilian Symposium on Iron Ore and $2^{\text {nd }}$ Brazilian Symposium on Agglomeration of Iron Ore, September $15^{\text {th }}$ to $18^{\text {th }}, 2014$, Belo Horizonte, MG, Brazil. 


\section{INTRODUCTION}

Dunite is a plutonic rock, whose main component is Olivine which has been naturally weathered over a long period of time; this rock has been extracted and processed since 1972 from the largest magnesium silicate ore mine in Spain and one of the largest in the world (see figure 1), located at the Spanish region of Galicia.

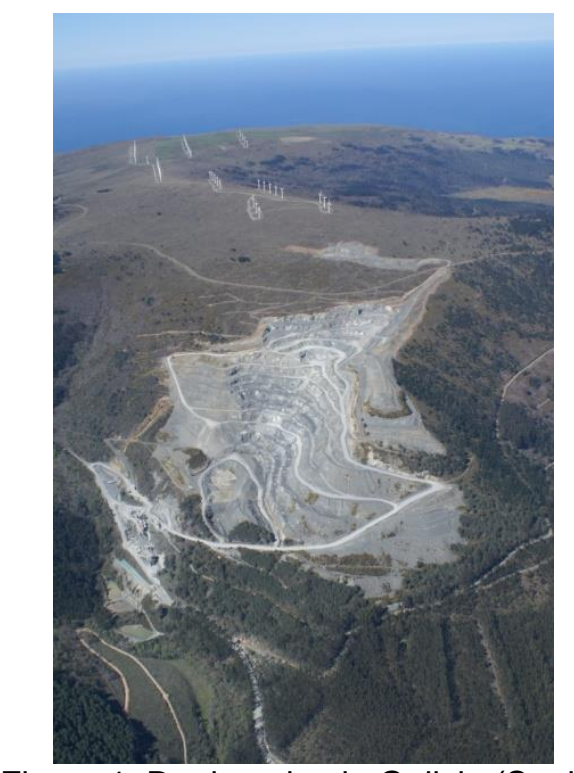

Figure 1: Dunite mine in Galicia (Spain)

The mine has a capacity of over one Mton per year; up to date, more than 27 Mton have been extracted, processed and commercialized.

The benefits of using PASEK Dunite in the blast furnace are well known as the product is being currently used all over Europe.

Due to internal logistical constraints, some plants which are interested in the use of Dunite lumps do not have the required infrastructure for it (additional silos, conveyor belts...) and have looked for alternatives in order to be able to use the product.

This paper describes a very innovative way of introducing small sized lumps of Dunite through the sinter bed, avoiding the need of investing on expensive logistical solutions.

\section{MATERIAL AND METHODS}

A preliminary lab study was carried out using a sinter pilot plant in which some Dunite mini lumps were introduced in order to analyze their behavior in the sinter.

In particular, the generation of an interphase Dunite/sinter was evaluated, including chemical composition, melting temperature and behavior of surrounding sinter.

On a later stage, a semi industrial test was carried out describing the behavior of the mini lumps as a whole.

\section{RESULTS AND DISCUSSION}

There are several benefits brought into the pig iron manufacturing process by using Dunite in lumpy form as a fluxing agent and slag conditioner.

\footnotetext{
* Technical contribution to the $44^{\text {th }}$ Ironmaking and Raw Materials Seminar, $15^{\text {rd }}$ Brazilian Symposium on Iron Ore and $2^{\text {nd }}$ Brazilian Symposium on Agglomeration of Iron Ore, September $15^{\text {th }}$ to $18^{\text {th }}, 2014$, Belo Horizonte, MG, Brazil.
} 
All of these benefits come from its favorable and well balanced physical and chemical properties, which has an effect on parameters of such importance for the pig iron production operation as permeability of the blast furnace load, effective alkalis removal and low energy consumption.

From a physical point of view (see Table1), there are three characteristics to be highlighted:

- Low softening and melting points (1.280 and $1.430^{\circ} \mathrm{C}$, respectively).

- Very high resistance to mechanical stresses (abrasion, shatter, impact...).

- Optimal grain size distribution: over $95 \%$ of the material in the range from 10 to $40 \mathrm{~mm}$.

Table 1: Dunite physical properties

\begin{tabular}{|l|c|}
\hline Characteristic & Value \\
\hline Crushing resistence (Baron) & $1400 \mathrm{gr} / \mathrm{cm}^{2}$ \\
\hline Abrasion index (Baron) & 4.5 \\
\hline Impact resistence (IRSID) in fines & $<10 \mathrm{~mm}=6 \%$ \\
\hline Abrasion resistence (MICUM) 200 T. in fines & $<10 \mathrm{~mm}=16 \%$ \\
\hline Thermal shock resistence 200 T. in fines & $<10 \mathrm{~mm}=5.3 \%$ \\
\hline Hardness (MOHS scale) & $6.5-7$ \\
\hline Softening point & $1280 \circ \mathrm{C}$ \\
\hline Fusion point & $1430 \circ \mathrm{C}$ \\
\hline Real density & 2.50 \\
\hline Aparent density & 1.70 \\
\hline Open porosity at 850 으 & $19.5 \%$ \\
\hline
\end{tabular}

Regarding chemical composition (see Table 2), its LOI content derives in an important increase on the specific surface of the rock. In fact, at the moderate temperature of $800^{\circ} \mathrm{C}$, an open porosity of $20 \%$ is reached (see Figure 2 ).

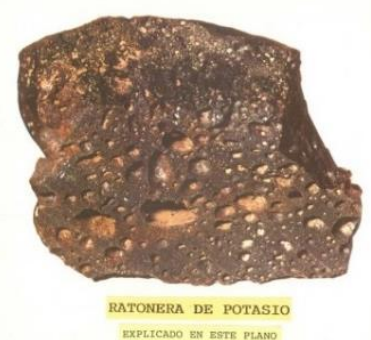

Figure 2: calcined Dunite open porosity

Table 2: Dunite chemical composition

\begin{tabular}{|l|c|c|c|c|c|c|c|c|}
\hline \multirow{2}{*}{ Dunite } & \multicolumn{7}{|c|}{ Chemical Analysis } \\
\cline { 2 - 11 } & $\mathbf{M g O}$ & $\mathbf{S i O}_{2}$ & $\mathrm{Fe}_{203}$ & $\mathrm{Al}_{2} \mathrm{O}_{3}$ & $\mathbf{C a O}$ & $\mathrm{Na}_{2} \mathrm{O}$ & $\mathrm{K}_{2} \mathrm{O}$ & LOI \\
\hline Average & 37.19 & 40.98 & 8.72 & 2.50 & 1.92 & 0.12 & 0.15 & 8.19 \\
\hline Std. Dev & 0.05 & 0.33 & 0.17 & 0.18 & 0.26 & 0.02 & 0.01 & 0.99 \\
\hline
\end{tabular}

\footnotetext{
* Technical contribution to the $44^{\text {th }}$ Ironmaking and Raw Materials Seminar, $15^{\text {rd }}$ Brazilian Symposium on Iron Ore and $2^{\text {nd }}$ Brazilian Symposium on Agglomeration of Iron Ore, September $15^{\text {th }}$ to $18^{\text {th }}, 2014$, Belo Horizonte, MG, Brazil.
} 


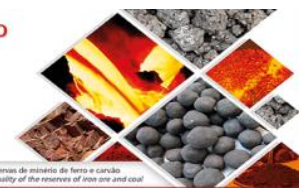

In this context, as opposed to other slag conditioners used in the industry, the fluxing activity of Dunite starts at the top of the shaft, right after entering the blast furnace. An analysis carried out by the Belgian Ceramic Institute digs into this effect (see Figure 3, where the fluxing activity of Dunite and of alternative products is represented by the white arrow).

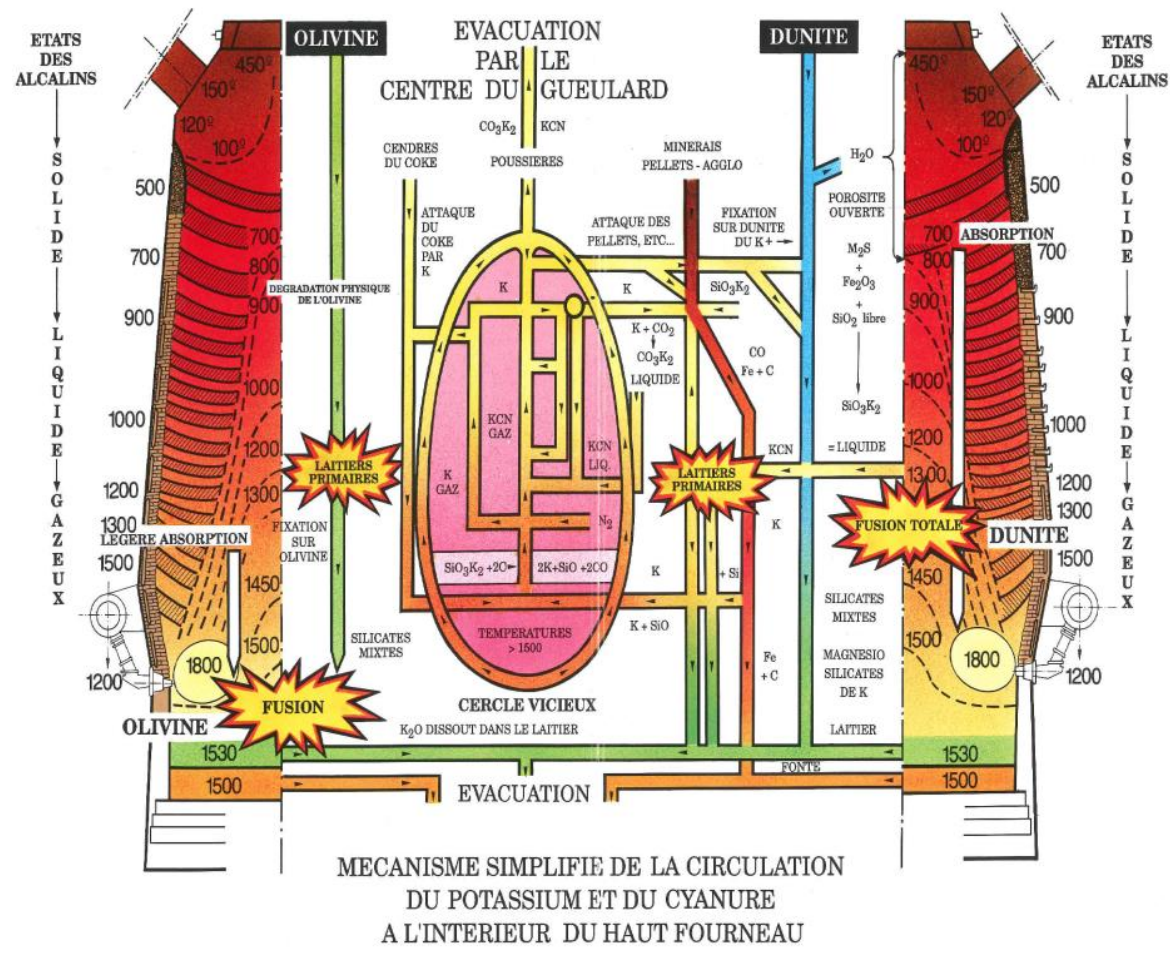

Figure 3: alkalis evacuation mechanisms

This is actually the main reason why Dunite has been used as a fluxing agent for the more than forty years, competing in the market with other products with higher $\mathrm{MgO}$ content but whose fluxing activity is much more limited, due to their higher softening / melting temperatures and a much more limited specific surface, that reduces the alkali absorption rate.

A comparison of the evacuation mechanisms of alkalis for both Dunite and other alternative products may be observed on Figure 3 .

\subsection{From Dunite Lumps... to Dunite Mini - Lumps}

It is well known that there is a global tendency since 2008 to an increase in the silica content of commercial iron ore.

Best quality ores with higher $\mathrm{Fe}$ content are becoming scarce and the ones coming from South America, Australia, Africa... have increasing amounts of $\mathrm{SiO}_{2}$ content. This tendency is believed to continue in the future.

In this context, many integrated plants are trying to:

- Optimize sinter productivity by maximizing the total Fe input through the sinter.

- Avoid the introduction of additional $\mathrm{SiO}_{2}$ into de sinter.

- Increase sinter basicity as much as the operation will allow.

This leads integrated plants to avoid as many raw materials outside iron ore and coke in the sinter bed as possible. In the case of Dunite, this is actually not a problem, quite the contrary, due to the above mentioned benefits of Dunite in the blast furnace

\footnotetext{
* Technical contribution to the 44 $4^{\text {th }}$ Ironmaking and Raw Materials Seminar, $15^{\text {rd }}$ Brazilian Symposium on Iron Ore and $2^{\text {nd }}$ Brazilian Symposium on Agglomeration of Iron Ore, September $15^{\text {th }}$ to $18^{\text {th }}, 2014$, Belo Horizonte, MG, Brazil.
} 


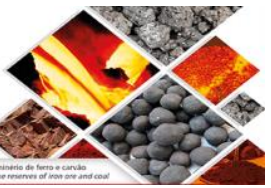

operation: the rock is therefore most of the times inserted in the operation directly in lumpy form.

But in some cases, certain plants face internal logistic constraints, due to a lack of availability of raw materials bunkers, conveyor belts, etc. and have looked for alternatives to profit from the benefits of using the lumpy form of Dunite.

Late in 2011 one of the largest steel producers came up with a very innovative idea of introducing $\mathrm{MgO}$ in lump form in the process while overcoming internal logistical constraints and without the need of carrying out a significant investment.

The innovation was to evaluate the introduction of several $\mathrm{MgO}$ bearing materials in lumpy form through the sinter bed (see Figure 4). The grain size of such lump certainly needs to be small enough to be compatible with the sinter raw materials and smaller than if introduced directly into the blast furnace (the maximum particle size in the sinter mix is in the range of $10 \mathrm{~mm}$ ).

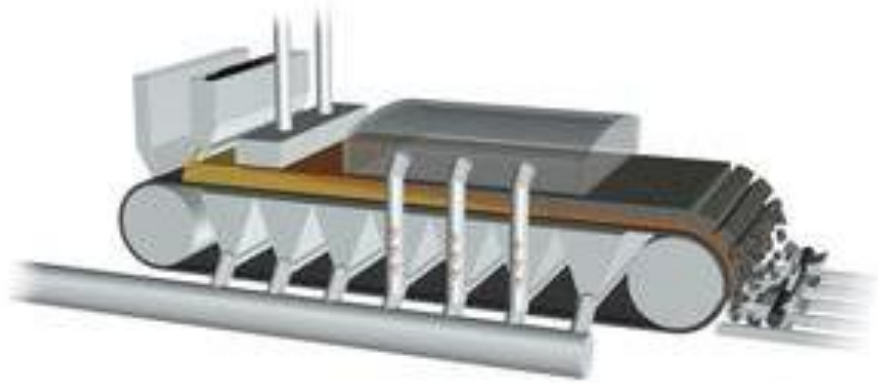

Figure 4: sinter bed scheme

Several tests were carried out with different types of materials, including Dunite and Olivine, with different grain size distributions.

Some conclusions of these tests were the following:

\subsubsection{Interphase $\mathrm{MgO}$ bearing material - sinter}

At normal sinter operating temperature, Dunite finds itself at an intermediate stage, just between its softening and melting points, and reacts partially with sinter, starting from the outside layer and progressing towards the core of the rock.

As a result, at the end of the sintering process, when sinter is broken into smaller pieces which will head by conveyor belt into the blast furnace, Dunite rocks are already "glued" and evenly distributed into the sinter pieces, while most olivine stones will just fall apart and be re-screened together with the sinter fines.

Figure 5 shows a micrography of a sinter piece (dark grey color) containing a Dunite mini lump (light grey color). The interphase Dunite - sinter may be observed (medium grey color). Such interphase is in fact the mechanism through which the Dunite mini lump remains stuck within the sinter matrix at the end of the sintering process.

* Technical contribution to the 44 ${ }^{\text {th }}$ Ironmaking and Raw Materials Seminar, $15^{\text {rd }}$ Brazilian Symposium on Iron Ore and $2^{\text {nd }}$ Brazilian Symposium on Agglomeration of Iron Ore, September $15^{\text {th }}$ to $18^{\text {th }}, 2014$, Belo Horizonte, MG, Brazil. 

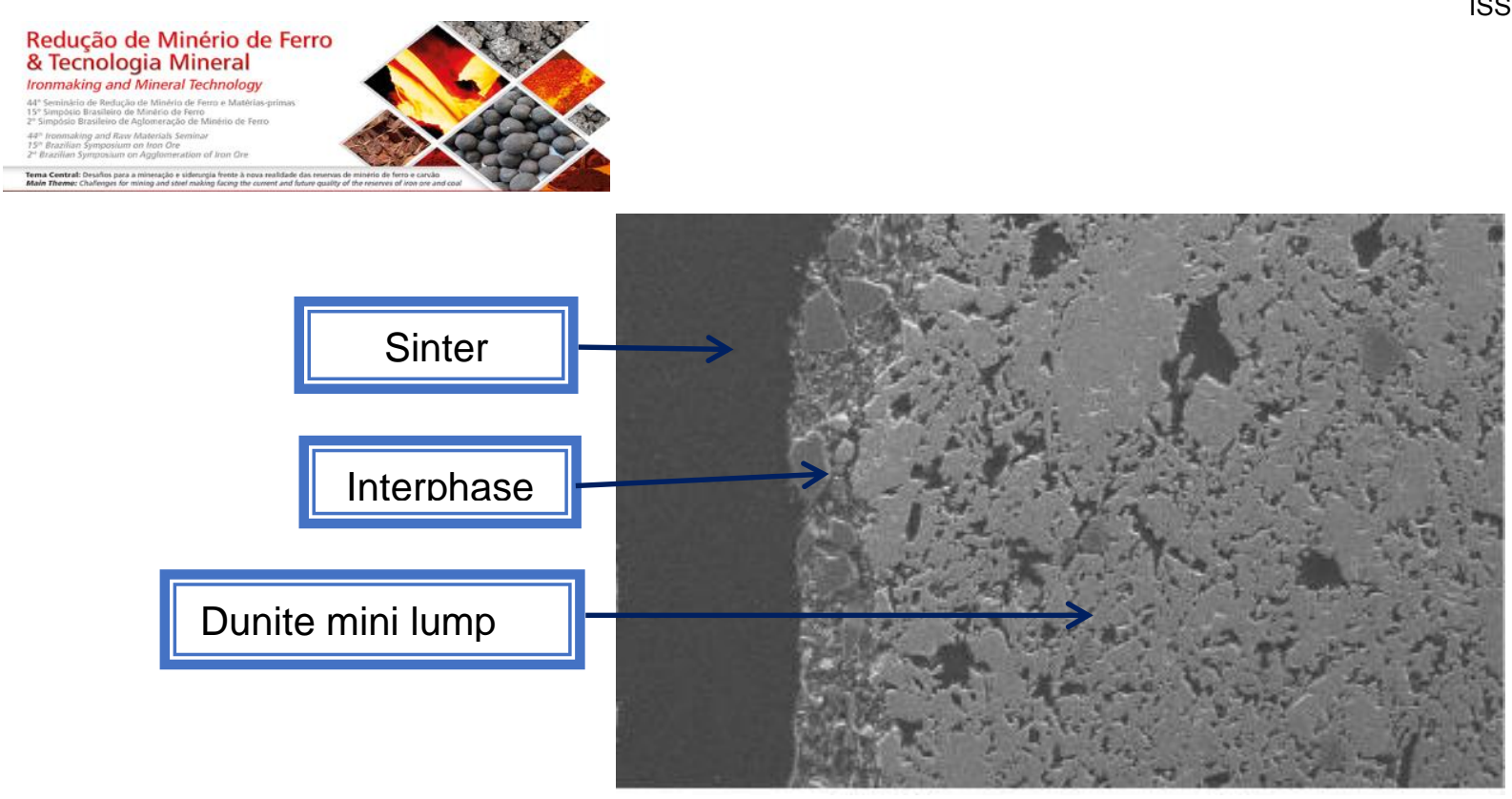

Figure 5: micrography of sinter, Dunite mini lump and interphase between both.

On the other hand, Olivine is in a raw state at this temperature and behaves like a fully inert rock placed on top of the matrix. As a result, the interphase olivine - sinter is almost non-existent and the "gluing effect" is therefore much more limited.

\subsubsection{Dunite mini lumps optimal size}

Several tests were carried out with different grain size distributions:

- In the first test a 5/15 mm grain size distribution was used; the result was not satisfactory, as the standard deviation of $\mathrm{MgO}$ in the bedding pile was higher than admissible, due to the segregation of the larger particles to the bottom of the pile.

- A second test was then performed with a $3 / 10 \mathrm{~mm}$. The results were much better than in the first case, as the segregation effect disappeared and the $\mathrm{MgO}$ was homogenously distributed along the sinter pile. A version of this trial was conducted using $1 / 10 \mathrm{~mm}$. No significant change was noticed between both, just a slight higher degree of reacted Dunite in the sinter bed, in this second case.

- A final test was then carried out with a 0/10 mm Dunite. The idea behind it was to analyze the effect of both products, Dunite fines $(0 / 3 \mathrm{~mm})$ and Dunite mini lumps $(3 / 10 \mathrm{~mm})$ in operation. The results here were also satisfactory and the segregation effect was also not noticeable in this trial.

In all of the above cases, an important additional effect regarding the use of Dunite was noticed: the non-generation of any type of dust while handling the product or using it in the operation, as opposed to other raw materials which were tested. This effect does bring several benefits, both from the operational point of view and from environmental issues.

\subsubsection{Effects on the sinter basicity}

A new concept was introduced: the so called "fake basicity". The idea is to achieve an increase of the sinter basicity (the fake basicity) by bringing inert components into the blast furnace through the sinter, without affecting its productivity. We can see this effect in the following example, with real operational figures:

Let us consider a sinter bed with a normal operation (a basicity of 2 is used in this example).

\footnotetext{
* Technical contribution to the 44 Ironmaking and Raw Materials Seminar, $15^{\text {rd }}$ Brazilian Symposium on Iron Ore and $2^{\text {nd }}$ Brazilian Symposium on Agglomeration of Iron Ore, September $15^{\text {th }}$ to $18^{\text {th }}, 2014$, Belo Horizonte, MG, Brazil.
} 


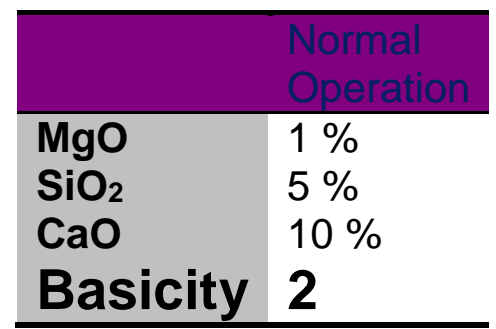

During the trial with mini lumps it was observed that some of the $\mathrm{MgO}$ and $\mathrm{SiO}_{2}$ remains inert (corresponding to the Dunite mini lump which has not reacted):

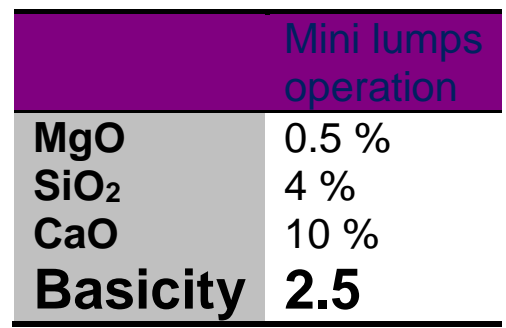

As a result, the basicity of the sinter increases in $25 \%$ while the productivity on the sinter bed remains unchanged.

\subsection{Comparative Analysis Dunite Mini Lumps / Olivine Fines}

One of the most important positive effects which Dunite mini lumps bring in the sinter application is linked to its precise grain size distribution: while most of the olivine fraction is in the range from 0 to $1 \mathrm{~mm}$ (up to $80 \%$ ), Dunite mini lumps content in the range below $1 \mathrm{~mm}$ is very limited.

This may be appreciated on Figure 6:

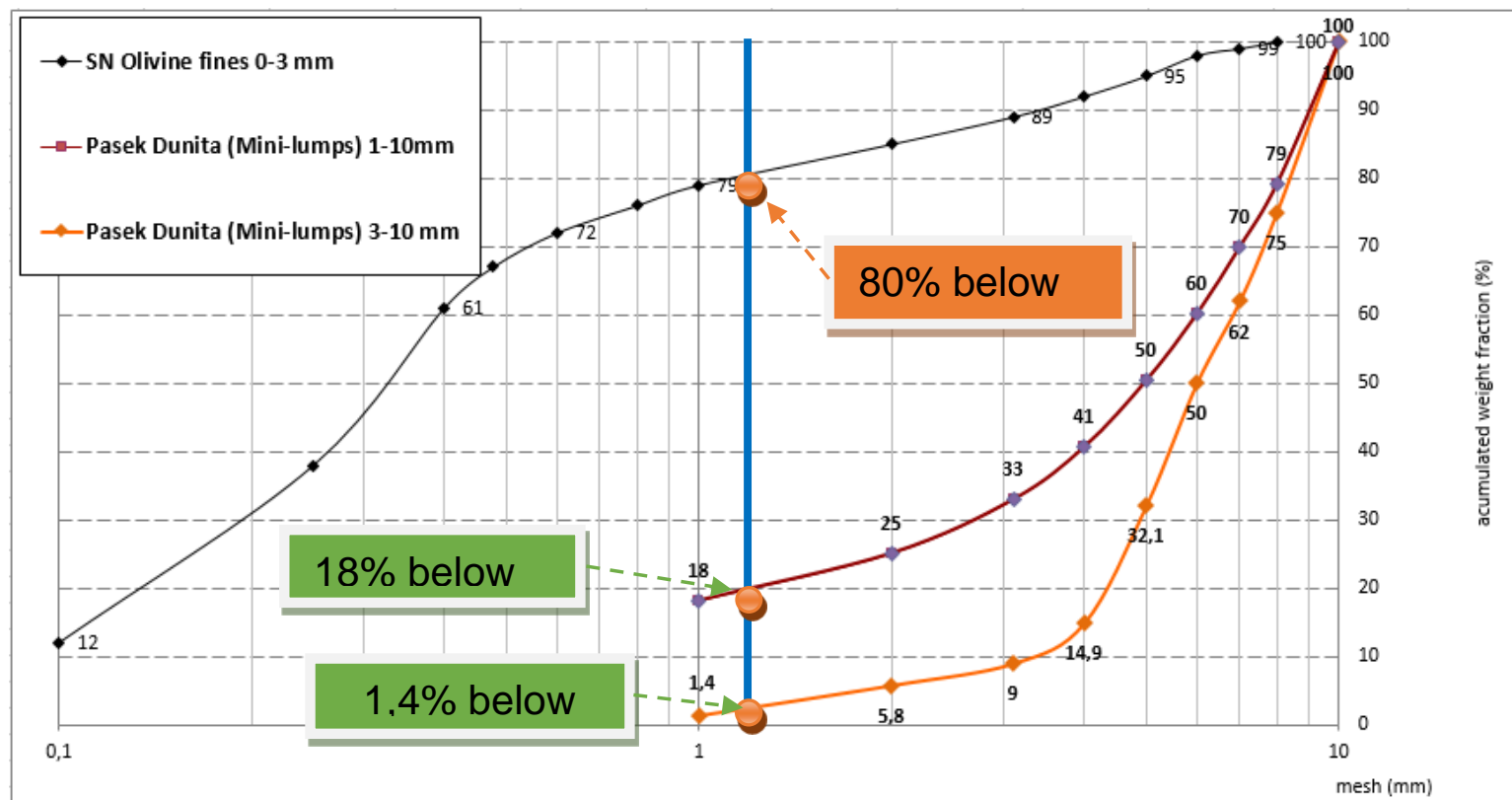

Figure 6: comparison between grain size distributions of Olivine and Dunite mini lumps $(1 / 10 \& 3 / 10)$.

* Technical contribution to the 44 Ironmaking and Raw Materials Seminar, $15^{\text {td }}$ Brazilian Symposium on Iron Ore and $2^{\text {nd }}$ Brazilian Symposium on Agglomeration of Iron Ore, September $15^{\text {th }}$ to $18^{\text {th }}, 2014$, Belo Horizonte, MG, Brazil. 
On industrial tests it was observed that while Olivine fines create large amounts of dust and powder while being handled at the sinter bed pile, Dunite mini lumps do not provoke this. A very positive effect of this comes from the environmental point of view.

\section{CONCLUSIONS}

$\checkmark$ The use of mini lumps is a very innovative method that some of the most important integrated plants are adopting in order to introduce $\mathrm{MgO}$ in their process in the most effective way.

$\checkmark$ Dunite shows the best balance between mechanical and physical properties for this application, as it effectively sticks to the sinter matrix and introduces a significant percentage of inert material does not affect its chemical composition and reaches the blast furnace as a lump.

$\checkmark$ The productivity of the sinter does not decrease when using Dunite mini lumps, but the "fake basicity" of the sinter increases.

$\checkmark$ Plants that want the most effective homogenization of $\mathrm{MgO}$ along the sinter bed chose the $3 / 10$ or $1 / 10 \mathrm{~mm}$ distributions, whereas plants which need to combine both fines and lumps during agglomeration should use the $0 / 10 \mathrm{~mm}$ distribution.

$\checkmark$ In some of the cases a very small increase of the slag level was observed (between 0.7 and $1.8 \mathrm{Kg} /$ ton of pig iron). In any case, the overall benefits of the introduction of the lumpy product through the sinter overcame this unwanted effect through the increase of productivity at the sinter plant.

$\checkmark$ The environmental evaluation of the test with Dunite was also successful, as no dust emissions were observed, no matter which grain size distribution which was used for the test.

\section{Acknowledgments}

Belgian Institute of Ceramics.

Esteban Ruisanchez, PhD \& Mining Engineer.

Cristina Escudero, PhD \& Chemical Engineer.

Henk Van der Bruggen.

\section{BIBLIOGRAPHY}

1 Tirlocq J. Etude Comparative de deux Silicates de Magnesium, en tant qu' gents d'elimination du posasium en Haut Fourneau; 2009.

2 Verbenne R, Arango PC, Caballero R. Benefits of Dunite as MgO addiction for Sinter and blast Furnace; 2010.

* Technical contribution to the $44^{\text {th }}$ Ironmaking and Raw Materials Seminar, $15^{\text {rd }}$ Brazilian Symposium on Iron Ore and $2^{\text {nd }}$ Brazilian Symposium on Agglomeration of Iron Ore, September $15^{\text {th }}$ to $18^{\text {th }}, 2014$, Belo Horizonte, MG, Brazil. 